\title{
GMR
}

\section{Hypoxia facilitates epithelial-mesenchymal transition-mediated rectal cancer progress}

\author{
L.L. Sun, Z. Song, W.Z. Li and S.Y. Tang \\ School of Nursing, The Third Xiangya Hospital of Central South University, \\ Changsha, China \\ Corresponding author: S.Y. Tang \\ E-mail: siyuantangqwe@sina.com \\ Genet. Mol. Res. 15 (4): gmr15048936 \\ Received July 1, 2016 \\ Accepted September 1, 2016 \\ Published December 2, 2016 \\ DOI http://dx.doi.org/10.4238/gmr15048936 \\ Copyright $(2016$ The Authors. This is an open-access article distributed under the terms of \\ the Creative Commons Attribution ShareAlike (CC BY-SA) 4.0 License.
}

\begin{abstract}
Rectal cancer is a commonly observed tumor in clinics, and epithelial-mesenchymal transition (EMT) is very important for tumor invasion and metastasis. We established a rectal cancer HCT-116 cell hypoxia model and detected cell proliferation, invasion, and EMTrelated protein expression in this model, aiming to analyze the effect of hypoxia on rectal cancer cell EMT. Rectal cancer cell line HCT-116 was cultured in normoxic, hypoxic, or anaerobic environment, and hypoxiainducible factor- $1 \alpha$ (HIF-1 $\alpha)$ mRNA expression was detected in the cells by real-time PCR. Cell proliferation was tested by MTT assay; cell invasion was determined by transwell assay, and HIF-1 $\alpha$, epithelialcadherin, and Snail protein levels were evaluated by western blot analysis. HIF-1 $\alpha$ mRNA level significantly increased in the anaerobic group compared to that in the normoxic and hypoxic groups $(\mathrm{P}<0.05)$. HCT-116 cell proliferation in the anaerobic group was obviously higher than that in the other two groups, with the hypoxic group showing stronger proliferative ability than the normoxic group $(\mathrm{P}<0.05)$. Compared to the normoxic group, the HCT-116 cells demonstrated
\end{abstract}


enhanced cell invasion and migration in hypoxic and anaerobic groups. HIF-1 $\alpha$ and Snail expressions were upregulated, whereas epithelialcadherin expression had declined in the hypoxic and anaerobic groups, compared to those in the normal control $(\mathrm{P}<0.05)$. Therefore, hypoxia promoted rectal cancer cell progress by increasing HIF-1 $\alpha$ to induce EMT.

Key words: Hypoxia; HCT-116; HIF-1 $\alpha$; E-cadherin; Snail

\section{INTRODUCTION}

Rectal cancer is a common digestive malignant tumor observed in clinics, with a high mortality rate. Its poor prognosis is closely related to tumor invasion and metastasis, whereas invasion and metastasis are based on epithelial-mesenchymal transition (EMT) (Roy and Majumdar, 2012; Wang et al., 2013). EMT refers to the transformation of epithelium-derived cells to mesenchymal cells (Zhao et al., 2011). Epithelial-cadherin (E-cadherin) and Snail are directly or indirectly involved in EMT (Li et al., 2012).

Tumor microenvironment, mainly composed of different types of cells, extracellular matrix, signaling molecules, acid, hypoxia, and other factors, has been extensively studied in recent years (Fan et al., 2014; Xiong et al., 2015). It was pointed out that in the tumor microenvironment, cytokines, hypoxia, and signaling pathways may regulate the process of rectal cancer EMT (Thiery et al., 2009; Hongo et al., 2013).

Hypoxia-inducible factor- $1 \alpha$ (HIF-1 $\alpha)$ is overexpressed in the anoxic environment. It can bind to the hypoxia response element and activate the downstream target genes to promote tumor invasion and metastasis. This process is completed by regulating hypoxia signal and mediating hypoxia effects (Pez et al., 2011; Woo et al., 2011). Therefore, this study established a rectal cancer HCT-116 cell hypoxia model to analyze the effect of hypoxia on rectal cancer cell EMT.

\section{MATERIAL AND METHODS}

\section{Materials}

\section{Cells and reagents}

Rectal cancer cell line HCT-116 was obtained from the Institute of Basic Medical Sciences, Chinese Academy of Medical Sciences, China. Mouse anti-human HIF-1 $\alpha$, E-cadherin, and Snail polyclonal antibodies and alkaline phosphatase-labeled goat anti-mouse secondary antibody were purchased from Santa Cruz Biotechnology (Dallas, TX, USA). PCR primers were acquired from Boya Biotechnology Engineering Company (Shanghai, China). Transwell chamber was obtained from BD Company (San Jose, CA, USA).

\section{Instruments and equipment}

Cell incubator was purchased from Thermo Fisher Scientific (Waltham, MA, USA). Inverted microscope was obtained from Nikon (Minato-ku, Tokyo, Japan). PCR thermocycler was acquired from Biometra (Göttingen, Germany). Centrifuge was obtained from Beckman (Danvers, MA, USA). Refrigerator was purchased from SANYO (Moriguchi, Osaka, Japan).

Genetics and Molecular Research 15 (4): gmr15048936 


\section{Experimental methods}

\section{Cell culture}

Rectal cancer HCT-116 cells were maintained in RPMI-1640 medium and were incubated at $37^{\circ} \mathrm{C}$ in a $5 \% \mathrm{CO}_{2}$ environment.

\section{Hypoxia cultivation}

The cells were maintained in RPMI- 1640 medium at $1 \% \mathrm{O}_{2}, 37^{\circ} \mathrm{C}$, and $5 \% \mathrm{CO}_{2}$ for $6 \mathrm{~h}$.

\section{Anaerobic cultivation}

$\mathrm{CoCl}_{2}$ was added to the medium to induce anaerobic environment. Cells were cultured in RPMI-1640 containing $600 \mu \mathrm{M} \mathrm{CoCl}_{2}$ for $6 \mathrm{~h}$.

\section{Real-time PCR}

Total RNA was extracted using an RNeasy Mini Kit (QIAGEN, Germantown, MD, USA), following manufacturer protocols. $\mathrm{D}_{260 \mathrm{~mm}} / \mathrm{D}_{280 \mathrm{~nm}}$ ratio was calculated to evaluate the purity of extracted RNA. Total 200 ng RNA was used to obtain cDNA, after synthesizing the poly(A) tail. The primer sequences used in the experiments are listed in Table 1. PCR procedure included denaturation at $95^{\circ} \mathrm{C}$ for $30 \mathrm{~s}$, followed by 40 cycles of $95^{\circ} \mathrm{C}$ for $5 \mathrm{~s}$ and $60^{\circ} \mathrm{C}$ for $30 \mathrm{~s}$. Glyceraldehyde 3-phosphate dehydrogenase was selected as the internal reference. The relative expression level was calculated by the $2^{-\Delta \Delta \mathrm{Ct}}$ method.

\section{Table 1. Primers used for real-time PCR.}

\begin{tabular}{l|l|c|c}
\hline Gene & Primer sequences & Annealing temperature $\left({ }^{\circ} \mathrm{C}\right)$ & Product length $(\mathrm{bp})$ \\
\hline \multirow{2}{*}{ HIF- $1 \alpha$} & 5'-CACCATGAAGCCTACACTGTGTTTCC-3' & & 50 \\
\cline { 2 - 3 } & 5'-TTAAACCATTCGGCAGCAGCGG-3' & & 561 \\
\hline GAPDH & 5'-GCCAAGGTCATCCATGACAACTTTGG-3' & 60 & 314 \\
\cline { 2 - 3 } & 5'-GCCTGCTTCACCACCTTCTTGATGTC-3' & & \\
\hline
\end{tabular}

HIF-1 $\alpha$, hypoxia-inducible factor-1 $\alpha$; GAPDH, glyceraldehyde 3-phosphate dehydrogenase.

\section{MTT assay}

HCT-116 cells in logarithmic phase were treated with $20 \mu \mathrm{L} 5 \mathrm{mg} / \mathrm{mL}$ 3'-(4',5'-dimethylthiazol-2-yl)-2',5'-diphenyltetrazolium bromide. After 4-h incubation, the cells were treated with $150 \mu \mathrm{L}$ dimethyl sulfoxide, and the plate was read at $570 \mathrm{~nm}$ wavelength on a Microplate Reader (BioTek, Winooski, VT, USA).

\section{Transwell assays}

Invasion test: Matrigel was added to the transwell chamber at $4^{\circ} \mathrm{C}$ overnight. After the membrane of the transwell chamber was treated with serum-free medium at $37^{\circ} \mathrm{C}$ for $1 \mathrm{~h}$, HCT-116 cells were seeded in the upper chamber, whereas RPMI-1640 medium was added to the lower chamber. Following this, the membrane was stained with Giemsa and was observed under the microscope. 
Migration test: The cells were seeded in the upper chamber of the transwell chamber, with treated membrane, without Matrigel. RPMI-1640 medium was added to the lower chamber. Following this, the membrane was stained with Giemsa and was observed under the microscope.

\section{Western blot analysis}

Total protein was extracted and separated by $8 \%$ SDS-PAGE. After transferring and blocking at room temperature for $1 \mathrm{~h}$, the PVDF membrane was treated with 1:1200 HIF$1 \alpha$, E-cadherin, and Snail polyclonal antibodies at $4^{\circ} \mathrm{C}$ overnight. Next, the goat anti-rabbit secondary antibody was added to the membrane at room temperature for $1 \mathrm{~h}$. Finally, the membrane was developed by enhanced chemiluminescence.

\section{Statistical analysis}

All data analysis was performed using the SPSS17.0 software (IBM Corporation, Armonk, NY, USA). All experiments were performed in triplicates. The data are reported as means \pm standard deviation. The chi-square test and the $t$-test were used for comparison between groups. $\mathrm{P}<0.05$ was considered statistically significance.

\section{RESULTS}

\section{HIF-1 $\alpha$ mRNA expression in HCT-116 cells after hypoxia or anaerobic treatment}

Real-time PCR was performed to test HIF-1 $\alpha$ mRNA expression in HCT-116 cells cultured under normoxic, hypoxic, or anaerobic condition. HIF-1 $\alpha$ mRNA level significantly increased in the anaerobic group, compared to that in the normoxic and hypoxic groups $(\mathrm{P}<0.05$; Figure 1$)$.

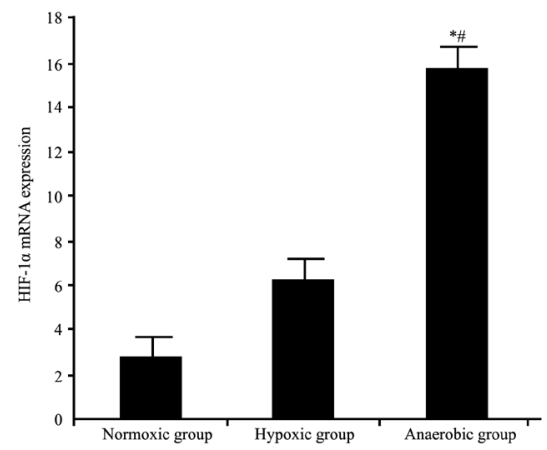

Figure 1. Hypoxia-inducible factor-1 $\alpha$ (HIF-1 $\alpha$ ) mRNA expression in HCT-116 cells after hypoxia or anaerobic treatment. ${ }^{*} \mathrm{P}<0.05$, compared to the normoxic group. ${ }^{*} \mathrm{P}<0.05$, compared to the hypoxic group.

\section{HCT-116 cell proliferation after hypoxia or anaerobic treatment}

HCT-116 cell viability after hypoxia or anaerobic treatment was detected. HCT-116 cells proliferated with time. HCT-116 cell proliferation in the anaerobic group was obviously

Genetics and Molecular Research 15 (4): gmr15048936 
higher than that in the other two groups, with hypoxic group showing stronger proliferative ability than the normoxic group $(\mathrm{P}<0.05$; Figure 2$)$.

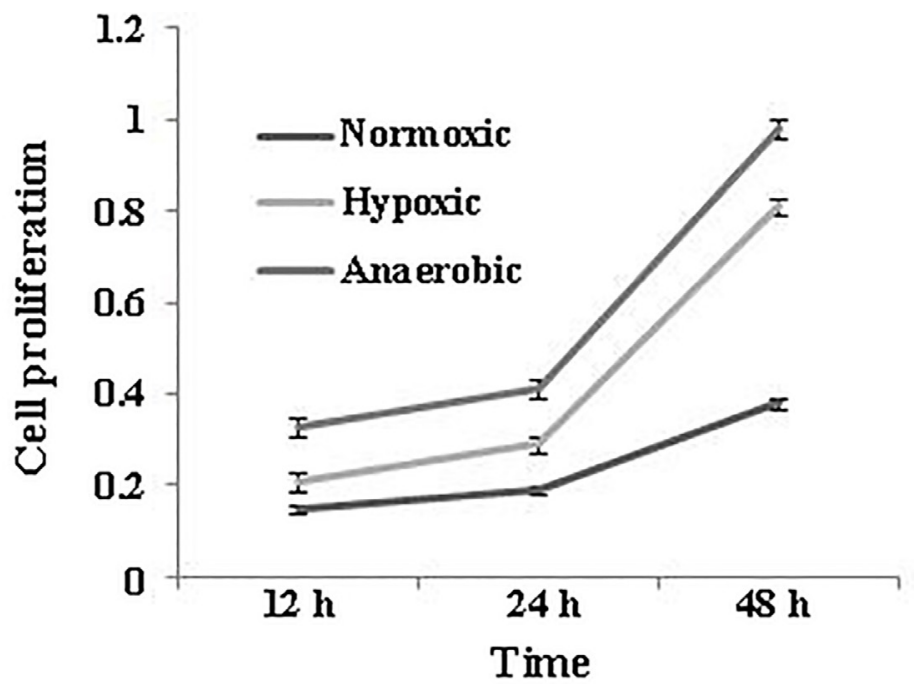

Figure 2. HCT-116 cell proliferation after hypoxia or anaerobic treatment.

\section{HCT-116 cell invasion and migration after hypoxia or anaerobic treatment}

Transwell assay was performed to determine HCT-116 cell invasion and migration after hypoxia or anaerobic treatment. Compared to the normoxic group, HCT-116 cells demonstrated enhanced cell invasion and migration in the hypoxic and anaerobic groups $(\mathrm{P}$ $<0.05)$. Anaerobic group presented obviously higher cell invasion and migration than the hypoxic group $(\mathrm{P}<0.05$; Figure 3$)$.

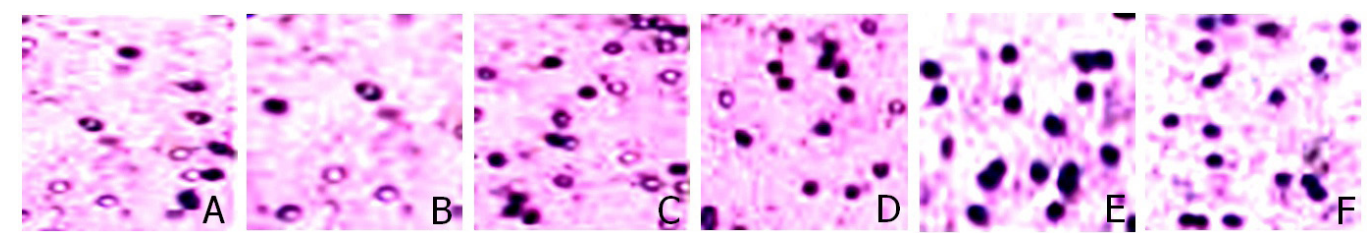

Figure 3. HCT-116 cell invasion and migration after hypoxia or anaerobic treatment (400X). A. Normoxic group invasion; B. normoxic group migration; C. hypoxic group invasion; D. hypoxic group migration; E. anaerobic group invasion; $\mathbf{F}$. anaerobic group migration.

\section{HIF-1 $\alpha$, E-cadherin, and Snail protein expressions after hypoxia or anaerobic treatment}

HIF-1 $\alpha$, E-cadherin, and Snail protein expressions were evaluated after hypoxia or anaerobic treatment. HIF-1 $\alpha$ and Snail expressions were upregulated, whereas E-cadherin level had declined in hypoxic and anaerobic groups compared to those in the normal control $(\mathrm{P}<0.05$; Figures 4 and 5).

Genetics and Molecular Research 15 (4): gmr15048936 


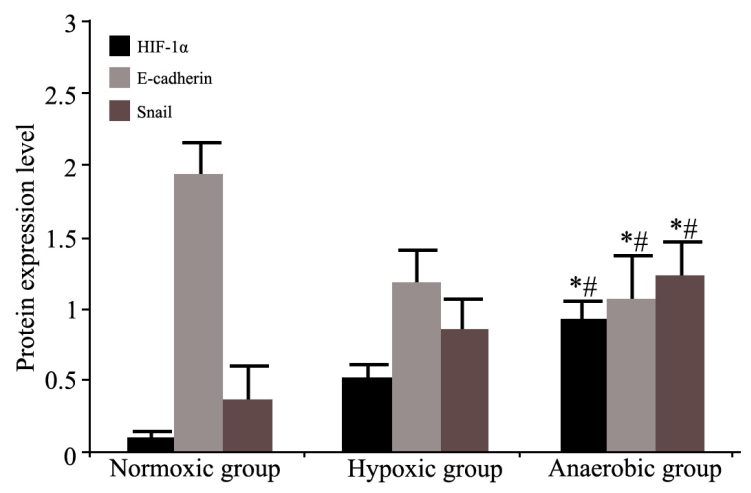

Figure 4. Hypoxia-inducible factor-1 $\alpha$ (HIF-1 $\alpha$ ), epithelial-cadherin (E-cadherin), and Snail protein expression analysis after hypoxia or anaerobic treatment. ${ }^{*} \mathrm{P}<0.05$, compared to normoxic group. ${ }^{*} \mathrm{P}<0.05$, compared to hypoxic group.

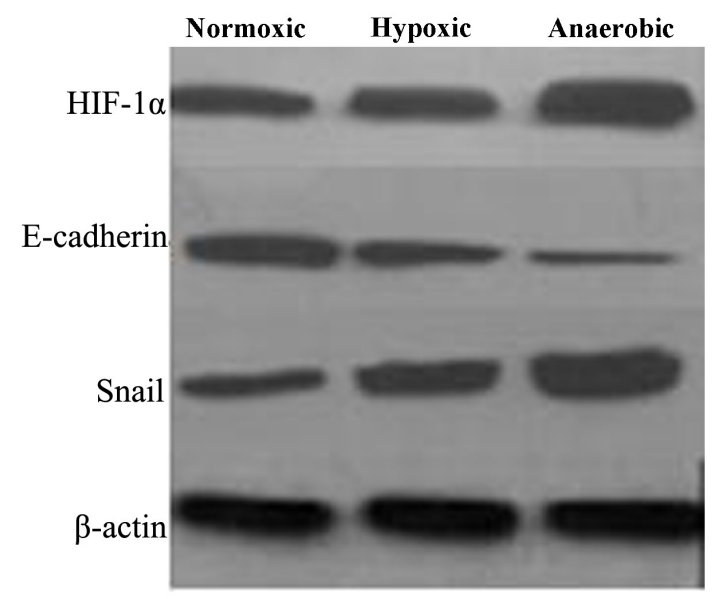

Figure 5. Hypoxia-inducible factor- $1 \alpha$ (HIF-1 $\alpha$ ), epithelial-cadherin (E-cadherin), and Snail protein expressions after hypoxia or anaerobic treatment. $\beta$-actin was used as a loading control.

\section{DISCUSSION}

Recurrence and metastasis are the main causes of death in rectal cancer patients, leading to excess oxygen consumption and oxygen undersupply (Trisciuoglio et al., 2010). It has been shown that hypoxic microenvironment may induce tumor cell apoptosis and suppress tumor growth and proliferation through a series of signaling pathways (Spivak-Kroizman et al., 2013). Tissue hypoxia can also elevate the malignancy of tumor cells, especially by inducing EMT (Savagner, 2010). In this study, we cultured rectal cancer HCT-116 cells under anaerobic, normoxic, and hypoxic conditions and tested cell proliferation, invasion, and EMTrelated protein expressions, to analyze the effect of hypoxia on rectal cancer cell EMT and its related mechanisms.

Real-time PCR was performed to detect HIF-1 $\alpha$ mRNA expression in HCT-116 cells, cultured under normoxic, hypoxic, or anaerobic condition. It was found that HIF-1 $\alpha$ 
mRNA level significantly increased in anaerobic and hypoxic groups, compared to that in the normoxic group. Research has demonstrated that HIF-1 $\alpha$ expression level is closely related to the oxygen level. Sufficient oxygen supply maintains HIF-1 $\alpha$ at low levels, whereas severe hypoxia may induce HIF-1 $\alpha$ overexpression, promoting tumor cell response to hypoxic state (Copple, 2010; Wu et al., 2014).

While studying the effect of hypoxia on rectal cancer HCT-116 cell behavior, we found that HCT-116 cells proliferated with time. HCT-116 cell proliferation in the anaerobic group was obviously higher than that in the other two groups, with the hypoxic group presenting stronger proliferative ability than the normoxic group. This suggested that hypoxia could increase the proliferation of HCT-116 cells.

This study further investigated the influence of hypoxia on HCT-116 cell invasion and migration. Compared to the normoxic group, HCT-116 cells demonstrated enhanced cell invasion and migration in the hypoxic and anaerobic groups. Anaerobic group presented obviously higher cell invasion and migration than the hypoxic group. This indicated that hypoxic conditions might enhance HCT-116 cell invasion and migration, as their invasion and migration obviously increased following aggravation of hypoxia.

It has been observed that most malignant tumor cells undergo EMT, which is the basic requirement for tumor cell invasion of surrounding tissues and for metastasis (Gulhati et al., 2011; Makrodouli et al., 2011). In addition, EMT is regulated by E-cadherin and Snail (Larriba et al., 2010). This study observed that HIF-1 $\alpha$ and Snail expressions were upregulated, whereas E-cadherin level had declined in hypoxic and anaerobic groups compared to those in the normal control. E-cadherin is one the most important regulatory factors involved in the process of EMT (Qin et al., 2016). Tumor cells with lower E-cadherin expression present stronger migration and invasion abilities, suggesting that E-cadherin is correlated to tumor metastasis (Hwang et al., 2011). Snail can inhibit E-cadherin expression to induce EMT, thus promoting tumor invasion and metastasis (Galván et al., 2010; Zheng et al., 2015).

Under anaerobic conditions, rectal cancer HCT-116 cells showed HIF- $1 \alpha$ level elevation, enhanced cell proliferation, downregulated E-cadherin expression, and increased Snail level, thus promoting EMT. However, more in-depth investigations are required to clarify the specific mechanism of EMT in rectal cancer hypoxia. Regulation of the hypoxic microenvironment may become the new research direction for clinical treatment of rectal cancer.

\section{Conflicts of interest}

The authors declare no conflict of interest.

\section{ACKNOWLEDGMENTS}

We thank the anonymous reviewers for reviewing this manuscript.

\section{REFERENCES}

Copple BL (2010). Hypoxia stimulates hepatocyte epithelial to mesenchymal transition by hypoxia-inducible factor and transforming growth factor-beta-dependent mechanisms. Liver Int. 30: 669-682. http://dx.doi.org/10.1111/j.14783231.2010.02205.x

Fan L, Feng Y, Wan HY, Ni L, et al. (2014). Hypoxia induces dysregulation of local renin-angiotensin system in mouse Lewis lung carcinoma cells. Genet. Mol. Res. 13: 10562-10573. http://dx.doi.org/10.4238/2014.December.12.19

Genetics and Molecular Research 15 (4): gmr15048936 
Galván JA, González MV, Crespo G, Folgueras MV, et al. (2010). Snail nuclear expression parallels higher malignancy potential in neuroendocrine lung tumors. Lung Cancer 69: 289-295. http://dx.doi.org/10.1016/j.lungcan.2009.12.010

Gulhati P, Bowen KA, Liu J, Stevens PD, et al. (2011). mTORC1 and mTORC2 regulate EMT, motility, and metastasis of colorectal cancer via RhoA and Rac1 signaling pathways. Cancer Res. 71:3246-3256.http://dx.doi.org/10.1158/00085472.CAN-10-4058

Hongo K, Tsuno NH, Kawai K, Sasaki K, et al. (2013). Hypoxia enhances colon cancer migration and invasion through promotion of epithelial-mesenchymal transition. J. Surg. Res. 182: 75-84.http://dx.doi.org/10.1016/j.jss.2012.08.034

Hwang WL, Yang MH, Tsai ML, Lan HY, et al. (2011). SNAIL regulates interleukin-8 expression, stem cell-like activity, and tumorigenicity of human colorectal carcinoma cells. Gastroenterology 141: 279-291, 291.e1-291.e5. http:// dx.doi.org/10.1053/j.gastro.2011.04.008

Larriba MJ, Bonilla F and Muñoz A (2010). The transcription factors Snail1 and Snail2 repress vitamin D receptor during colon cancer progression. J. Steroid Biochem. Mol. Biol. 121: 106-109. http://dx.doi.org/10.1016/j.jsbmb.2010.01.014

Li Y, Wang W, Wang W, Yang R, et al. (2012). Correlation of TWIST2 up-regulation and epithelial-mesenchymal transition during tumorigenesis and progression of cervical carcinoma. Gynecol. Oncol. 124: 112-118. http://dx.doi. org/10.1016/j.ygyno.2011.09.003

Makrodouli E, Oikonomou E, Koc M, Andera L, et al. (2011). BRAF and RAS oncogenes regulate Rho GTPase pathways to mediate migration and invasion properties in human colon cancer cells: a comparative study. Mol. Cancer 10: 118. http://dx.doi.org/10.1186/1476-4598-10-118

Pez F, Dayan F, Durivault J, Kaniewski B, et al. (2011). The HIF-1-inducible lysyl oxidase activates HIF-1 via the Akt pathway in a positive regulation loop and synergizes with HIF-1 in promoting tumor cell growth. Cancer Res. 71: 1647-1657. http://dx.doi.org/10.1158/0008-5472.CAN-10-1516

Qin Y, Tang B, Hu CJ, Xiao YF, et al. (2016). An hTERT/ZEB1 complex directly regulates E-cadherin to promote epithelial-to-mesenchymal transition (EMT) in colorectal cancer. Oncotarget 7: 351-361.

Roy S and Majumdar AP (2012). Signaling in colon cancer stem cells. J. Mol. Signal. 7: 11. http://dx.doi.org/10.1186/1750$\underline{2187-7-11}$

Savagner P (2010). The epithelial-mesenchymal transition (EMT) phenomenon. Ann. Oncol. 21 (Suppl 7): vii89-vii92. http://dx.doi.org/10.1093/annonc/mdq292

Spivak-Kroizman TR, Hostetter G, Posner R, Aziz M, et al. (2013). Hypoxia triggers hedgehog-mediated tumor-stromal interactions in pancreatic cancer. Cancer Res. 73: 3235-3247. http://dx.doi.org/10.1158/0008-5472.CAN-11-1433

Thiery JP, Acloque H, Huang RY and Nieto MA (2009). Epithelial-mesenchymal transitions in development and disease. Cell 139: 871-890.http://dx.doi.org/10.1016/j.cell.2009.11.007

Trisciuoglio D, Gabellini C, Desideri M, Ziparo E, et al. (2010). Bcl-2 regulates HIF-1 $\alpha$ protein stabilization in hypoxic melanoma cells via the molecular chaperone HSP90. PLoS One 5: e11772. http://dx.doi.org/10.1371/journal. pone. 0011772

Wang H, Wang HS, Zhou BH, Li CL, et al. (2013). Epithelial-mesenchymal transition (EMT) induced by TNF- $\alpha$ requires AKT/GSK-3ß-mediated stabilization of snail in colorectal cancer. PLoS One 8: e56664.http://dx.doi.org/10.1371/ journal.pone.0056664

Woo S, Lee BL, Yoon J, Cho SJ, et al. (2011). Constitutive activation of signal transducers and activators of transcription 3 correlates with better prognosis, cell proliferation and hypoxia-inducible factor- $1 \alpha$ in human gastric cancer. Pathobiology 78: 295-301.http://dx.doi.org/10.1159/000321696

Wu Y, Mao F, Zuo X, Moussalli MJ, et al. (2014). 15-LOX-1 suppression of hypoxia-induced metastatic phenotype and HIF-1 $\alpha$ expression in human colon cancer cells. Cancer Med. 3: 472-484. http://dx.doi.org/10.1002/cam4.222

Xiong J, Zhu FF and Nie MF (2015). Hypoxia-inducible factor-2 $\alpha$ (HIF-2 $\alpha$ ) mediates the effects of hypoxia on the promotion of HeLa cell viability, colony formation, and invasion capacity in vitro. Genet. Mol. Res. 14: 3281-3292. http://dx.doi.org/10.4238/2015.April.13.7

Zhao JH, Luo Y, Jiang YG, He DL, et al. (2011). Knockdown of $\beta$-Catenin through shRNA cause a reversal of EMT and metastatic phenotypes induced by HIF-1 $\alpha$. Cancer Invest. 29: 377-382. http://dx.doi.org/10.3109/07357907.2010.5 $\underline{12595}$

Zheng M, Jiang YP, Chen W, Li KD, et al. (2015). Snail and Slug collaborate on EMT and tumor metastasis through miR-101-mediated EZH2 axis in oral tongue squamous cell carcinoma. Oncotarget 6: 6797-6810. http://dx.doi. org/10.18632/oncotarget. 3180

Genetics and Molecular Research 15 (4): gmr15048936 